\title{
ANALISIS BIAYA DAN PENDAPATAN PETERNAK AYAM BROILER DI KOTA SEMARANG
}

\section{THE ANALYSIS OF COST AND INCOME BROILER BREEDERS IN SEMARANG CITY}

\author{
Dwi Umi Mulyaningsih, W. D. Prastiwi, dan W. Sarengat \\ Program Studi S1 Peternakan \\ Fakultas Peternakan dan Pertanian Universitas Diponegoro Semarang
}

\section{Email: umidwi@rocketmail.com}

\begin{abstract}
The research intends to know the cost and income broiler breeders in Semarang City. Reasearch obtained by breeders in Gunungpati district and Mijen district. The method use in this research is survey method with purposive sampling method. The study look place from January until February 2015. Data collection consisted of primary and secondary data. Primary data obtained from the observation and interviews of respondents. The results of this study show calculation there is no difference in cost and income between broiler breeders in Gunungpati district with Mijen district. The results show that the average cost of broiler breeders in Gunungpati district Rp 198.003.520,04 and in Mijen district Rp 183.488.974,87 and the average income of broiler breeders in Gunungpati district $\mathrm{Rp}$ 14.422.095 and in Mijen district $\mathrm{Rp}$ 17.209.832. There is no difference in cost broiler breeders in Gunungpati district and Mijen district with significance value $0,627>0,05$, and there is no difference in income broiler breeders in Gunungpati district and Mijen district with significance 0,653>0,05.
\end{abstract}

Keywords: Broiler chicken, cost, income, breeders.

\begin{abstract}
ABSTRAK
Penelitian ini bertujuan untuk mengetahui biaya dan pendapatan peternak ayam broiler di Kota Semarang. Penelitian diperoleh dari peternak di Kecamatan Gunungpati dan Kecamatan Mijen. Metode yang digunakan pada penelitian ini adalah metode survey dengan metode purposive sampling. Penelitian ini berlangsung dari Januari sampai Februari 2015. Data yang diambil berupa data primer dan data sekunder. Data primer diperoleh dari observasi dan wawancara kepada responden. Penelitian ini menunjukkan hasil tidak ada perbedaan biaya dan pendapatan peternak ayam broiler di Kecamatan Gunungpati dan Kecamatan Mijen. Hasil penelitian menunjukkan rata-rata biaya peternak ayam broiler di Kecamatan Gunungpati Rp 198.003.520,04 dan di Kecamatan Mijen Rp 183.488.974,87 dan rata-rata pendapatan peternak ayam broiler di Kecamatan Gunungpati Rp 14.422.095 dan di Kecamatan Mijen Rp 17.209.832, tidak terdapat perbedaan biaya peternak ayam broiler di Kecamatan Gunungpati dan Kecamatan Mijen dengan nilai signifikansi 0,627>0,05 dan tidak terdapat
\end{abstract}


perbedaan pendapatan peternak ayam broiler di Kecamatan Gunungpati dan Kecamatan Mijen dengan nilai signifikansi 0,653>0,05.

Kata kunci: ayam broiler, biaya, pendapatan, peternak

\section{PENDAHULUAN}

Jumlah penduduk Indonesia mengalami peningkatan dari tahun ke tahun. Pada tahun 2014 jumlah penduduk Indonesia sebesar 252.124.458 jiwa, sedangkan jumlah penduduk di Kota Semarang adalah 1.739.989 jiwa dengan luas wilayah 373,67 $\mathrm{km}^{2}$ (BPS Kota Semarang, 2014). Hal ini menimbulkan konsekuensi pada pertumbuhan ekonomi di Indonesia yang semakin meningkat, serta makin meningkatnya kemungkinan jumlah masyarakat Indonesia yang semakin sadar tentang pentingnya kebutuhan gizi. Peningkatan kebutuhan pangan, baik bahan pangan hewani, maupun nabati merupakan konsekuensi dari peningkatan kesadaran tentang pentingnya kebutuhan gizi. Daging ayam merupakan hasil peternakan yang banyak diminati oleh banyak masyarakat. Tingkat konsumsi ayam broiler di Indonesia pada tahun 2010 mencapai angka 8 kg/ kapita/ tahun, kemudian pada tahun 2012 meningkat menjadi 10 kg/ kapita/ tahun (Ditjen Peternakan Kementan, 2013).

Pendapatan peternak ayam dipengaruhi oleh faktor-faktor antara lain banyaknya ayam yang terjual dan harga yang ditentukan. Daging ayam banyak diperoleh di pasar-pasar tradisional maupun modern karena peningkatan konsumsi daging ayam paling pesat dibandingkan daging lainnya. Pendapatan peternak ayam broiler di Kecamatan Gunungpati dan Mijen Kota Semarang diduga memiliki perbedaan biaya dan pendapatan, harga jual barang itu sendiri, jumlah anggota keluarga dan pendidikan (BPS Kecamatan Gunungpati dan Mijen, 2014).

Tujuan dari penelitian ini adalah untuk mengetahui perbedaan biaya dan pendapatan yang diterima oleh peternak ayam broiler yang berada di Kota Semarang dan mengetahui perbedaan pendapatan peternak ayam pada masingmasing wilayah. Manfaat dari penelitian ini adalah diharapkan dapat menjadi informasi yang berguna bagi para peternak ayam dalam penggunaan biaya untuk lebih mengefisienkan biaya yang dikeluarkan sehingga dapat meningkatkan pendapatan dan dapat memberi masukan serta gambaran bagi pihak yang berkepentingan dalam usaha beternak. Bagi peneliti dapat mengetahui dan menambah wawasan serta pengetahuan tentang beternak ayam broiler.

\section{BAHAN DAN METODE}

Penelitian dilaksanakan pada bulan Januari-Februari 2015. Lokasi yang dipilih untuk penelitian adalah di Kecamatan Mijen dan Kecamatan Gunungpati Kota Semarang.

\section{METODE PENELITIAN}

Metode yang digunakan dalam pengumpulan data adalah metode studi kasus yaitu metode penelitian dengan mencatat beberapa elemen, kemudian masing-masing elemen diteliti secara lebih mendalam, dengan mengambil data 
primer dan sekunder. Informasi dikumpulkan dengan daftar pertanyaan yang sudah disiapkan sebelumnya.

\section{ANALISIS DATA}

Data primer dan data sekunder yang telah dikumpulkan dari hasil wawancara dan observasi kemudian ditabulasi dan selanjutnya diolah untuk mengetahui biaya tetap, biaya tidak tetap dan penerimaan peternak ayam broiler. Data diperoleh dengan cara memberi kuisioner yang terdapat pada lampiran 1. Variabel yang termasuk dalam perhitungan tersebut adalah penerimaan dari penjualan ayam broiler. Biaya pemasaran yang meliputi biaya tetap terdiri retribusi, penyusutan peralatan dan pembayaran gaji pegawai tetap. Biaya tidak tetap meliputi biaya transportasi, kandang, biaya vaksin, pakan dan vitamin. Data yang diperoleh di analisis secara kuantitatif. Analisis kuantitatif adalah analisis yang berhubungan dengan angka sehingga dapat diuji secara statistik (Sugiyono, 2010).

Proses analisis kuantitatif dapat dilakukan dengan dua tahapan yaitu,

1. Tahapan pengolahan data

Data yang telah diperoleh dari penelitian terlebih dahulu diolah kemudian disiapkan dalam bentuk tabel yang selanjutnya akan dilakukan analisis.

2. Tahapan analisis data

Analisis data dilakukan untuk membahas dan mengolah data yang telah didapat dari penelitian. Data yang didapat dianalisis secara kuantitatif dengan menggunakan bantuan program SPSS 16 for Windows.

Data biaya produksi dan penerimaan yang sudah dikelompokkan selanjutnya dianalisis rugi laba, sehingga dapat diketahui pendapatan pedagang daging ayam, adapun rumusnya:

1. Biaya total dapat dirumuskan (Prawirokusumo, 1991)

$\mathrm{TC}=\mathrm{TFC}+\mathrm{TVC}$.

Dimana: $\quad \mathrm{TC} \quad=$ Biaya total $(\mathrm{Rp} / \mathrm{hari})$

TFC = Biaya tetap total $(\mathrm{Rp} / \mathrm{hari})$

TVC = Biaya variabel total $(\mathrm{Rp} / \mathrm{hari})$

2. Pendapatan dan penerimaan total dapat dirumuskan (Rasyaf, 2002)

$\mathrm{Pd}=\mathrm{TR}-\mathrm{TC}$

$\mathrm{TR}=\mathrm{Y} . \mathrm{Py}$

Dimana:

$\mathrm{Pd} \quad=$ Pendapatan $(\mathrm{Rp} / \mathrm{hari})$

$\mathrm{TR}=$ Penerimaan $(\mathrm{Rp} / \mathrm{hari})$

$\mathrm{TC}=$ Biaya total $(\mathrm{Rp} / \mathrm{hari})$

$\mathrm{Y} \quad=$ Jumlah produk yang dihasilkan $(\mathrm{kg} / \mathrm{hari})$

Py = Harga Produk $(\mathrm{Rp} / \mathrm{kg}$ daging $)$

\section{HASIL DAN PEMBAHASAN}

Kota Semarang adalah merupakan Ibukota Jawa Tengah dengan luas wilayah 373,67 km² dan jumlah penduduk sebesar 1.739.989 jiwa. Batas wilayah Kota Semarang secara administratif adalah sebelah Barat Kabupaten Kendal, 
sebelah Timur Kabupaten Demak, sebelah Selatan Kabupaten Semarang dan sebelah Utara Laut Jawa dengan garis pantai mencapai 13,6 kilometer. Secara topografis Kota Semarang terdiri dari daerah perbukitan, dataran rendah dan daerah pantai. Daerah pantai sebesar $65,22 \%$ wilayah adalah dataran dengan kemiringan $25 \%$ dan $37,78 \%$ wilayah merupakan daerah perbukitan dengan kemiringan $15-40 \%$. Wilayah Kota Semarang berada pada ketinggian antara 0 sampai dengan 348,00 mdpl (di atas permukaan air laut). Pada daerah perbukitan mempunyai ketinggian 90,56 - 348 mdpl yang diwakili oleh titik yang berlokasi di Jatingaleh dan Gombel, Semarang Selatan, Tugu, Mijen dan Gunungpati mempunyai ketinggian 0,75 mdpl (BPS Kota Semarang, 2014). Kecamatan Gunungpati Kota Semarang merupakan salah satu kecamatan yang berada di bagian Selatan Kota Semarang. Secara administratif Kecamatan Gunungpati terbagi menjadi 16 Kelurahan dengan total luas wilayah sebesar 5.292.901 Ha (BPS Kecamatan Gunungpati dan Mijen, 2014). Kecamatan Mijen memiliki wilayah yang terdiri atas daerah dataran rendah, dengan ketinggian mencapai 0 sampai 288 meter dari permukaan air laut. Gambaran umum secara administratif Kecamatan Mijen terbagi menjadi 14 Kelurahan dengan luas wilayah 6.833.077 $\mathrm{Km}^{2}$ (BPS Kecamatan Gunungpati dan Mijen, 2014).

Tabel 1. Identitas Responden Peternak Ayam

\begin{tabular}{|c|c|c|c|c|c|}
\hline \multirow[b]{2}{*}{ No } & \multirow[b]{2}{*}{ Identitas } & \multicolumn{4}{|c|}{ Kecamatan } \\
\hline & & Gunungpati & Persentase & Mijen & Persentase \\
\hline & & (orang) & $(\%)$ & (orang) & $(\%)$ \\
\hline 1 & Jumlah Peternak & 18 & 58,06 & 13 & 41,94 \\
\hline \multirow[t]{3}{*}{2} & Jenis Kelamin & & & & \\
\hline & Laki-laki & 17 & 94,4 & 12 & 92,3 \\
\hline & Perempuan & 1 & 5,6 & 1 & 7,7 \\
\hline \multirow[t]{6}{*}{3} & Umur (tahun) & & & & \\
\hline & $21-30$ & 1 & 5,6 & 2 & 15,3 \\
\hline & $31-40$ & 7 & 38,9 & 4 & 30,8 \\
\hline & $41-50$ & 5 & 27,7 & 4 & 30,8 \\
\hline & $51-60$ & 4 & 22,2 & 3 & 23,1 \\
\hline & $61-70$ & 1 & 5,6 & - & - \\
\hline \multirow[t]{4}{*}{4} & Pengalaman & & & & \\
\hline & Beternak (tahun) & & & & \\
\hline & $1-10$ & 15 & 83,3 & 9 & 69,2 \\
\hline & $11-20$ & 3 & 16,7 & 4 & 30,8 \\
\hline \multirow[t]{6}{*}{5} & Pendidikan & & & & \\
\hline & Tamat SD & 5 & 27,7 & 3 & 23,1 \\
\hline & Tamat SMP & 1 & 5,6 & - & - \\
\hline & Tamat SMA & 10 & 55,6 & 6 & 46,1 \\
\hline & Diploma & - & - & 1 & 7,7 \\
\hline & Sarjana & 2 & 11,1 & 3 & 23,1 \\
\hline
\end{tabular}

Sumber: Analisis Data Primer, 2015. 
Kecamatan Gunungpati memiliki potensi ternak unggas sebanyak hampir 350 ribu ekor dengan persentase terdiri atas hampir $44 \%$ ayam pedaging, ayam petelur $\pm 30 \%$, ayam kampung $\pm 26 \%$ dan itik $\pm 0,5 \%$ (BPS Kota Semarang, 2014).

Kecamatan Mijen juga memiliki ternak kecil yaitu kambing/domba sebanyak 3.111 ekor. Potensi ternak unggas di Kecamatan Mijen paling banyak jumlahnya adalah ayam petelur dengan persentase hampir $44 \%$, ayam pedaging $\pm 43 \%$, ayam kampung $10 \%$, itik $\pm 3 \%$ dan angsa hampir $1 \%$.

Responden dalam penelitian ini terdiri dari 31 responden sebagai peternak yang tergabung dalam 3 kemitraan dalam bidang peternakan yaitu, PT. Mustika, PT. Ganesha, dan PT. Ciomas. Sistem kandang yang dimiliki peternak ayam yaitu menggunakan kandang panggung yang terbuat dari susunan bambu baik lantai maupun dinding. Atap kandang terbuat dari genting, bahan ini digunakan karena mudah menyerap panas dibandingkan atap kandang yang menggunakan atap seng. Pada peternakan ayam broiler di lokasi penelitian baik di Kecamatan Gunungpati dan Kecamatan Mijen ayam broiler siap panen antara umur 33-38 hari. Aktivitas panen biasanya dilakukan pada pagi hari selama 2 hari. Pada peternakan di wilayah penelitian, peternak melakukan pemanenan rata-rata pada umur 35 hari. Inti kemitraan biasanya akan mendapatkan informasi dari peternak jika ayamnya sudah siap untuk di panen. Kegiatan pemanenan biasanya dilakukan pada sore dan malam hari selama 2 hari. Ayam yang akan dipanen biasanya dipuasakan selama 8-10 jam agar ayam tidak stress saat kegiatan pemanenan sedang dilaksanakan, kemudian ayam yang di panen tersebut di ambil lalu ditimbang bobotnya kemudian dimasukkan kedalam keranjang ayam. Hal ini sesuai dengan pendapat Fadilah (2013) yang menyatakan bahwa pemanenan ayam broiler dilakukan secara bertahap. Broiler adalah ayam yang dipelihara secara intensif, untuk memperoleh produksi daging yang optimal, sehingga dalam jangka waktu singkat dapat dimanfaatkan hasilnya (AAK, 1986). Pemasaran ayam broiler di lokasi penelitian ini dilakukan sesuai prosedur yang terdapat pada surat perjanjian atau kontrak antara peternak atau plasma dengan inti kemitraan. Rata-rata tenaga kerja yang digunakan oleh peternak ayam broiler di Kecamatan Gunungpati dan Kecamatan Mijen antara 1-3 orang. Upah yang diberikan berkisar antara Rp. 1.000.000,- sampai Rp. 2.000.000,-/bulan per orang.

Pengalaman beternak rata-rata di Kecamatan Gunungpati dan di Kecamatan Mijen selama 10 tahun. Lamanya peternak dalam menjalankan usaha beternak ayam broiler mempengaruhi penghasilan usaha ternak tersebut. Hal ini sesuai dengan pendapat Rasyaf (2000) yang menyatakan bahwa pengalaman beternak seorang peternak ayam dapat menunjukkan keberhasilan mengembangkan peternakan ayamnya.

Tingkat pendidikan yang paling banyak adalah tamat SMA sebanyak 10 orang di Kecamatan Gunungpati $(55,6 \%)$ dan 6 orang di Kecamatan Mijen $(46,1 \%)$. Tinggi rendahnya tingkat pendidikan peternak mempengaruhi dalam cara berfikir dan cara kerja dalam meningkatkan usahanya. Hal ini sesuai dengan pendapat Hernanto (1993) yang menyatakan bahwa tingkat pendidikan responden berpengaruh pada cara berfikir dan daya serap petani atau peternak terhadap inovasi dan teknologi pertanian. 
Rata-rata modal investasi peternak ayam broiler di Kecamatan Mijen lebih besar dibandingkan Kecamatan Gunungpati, yaitu di Kecamatan Mijen sebesar Rp. 249.149.793,- dan di Kecamatan Gunungpati sebesar Rp. 226.786.470,-Biaya investasi terbesar peternak di Kecamatan Gunungpati adalah kandang sebesar Rp. 189.500.000,- atau 83,55\% dan di Kecamatan Mijen kandang sebesar Rp. 213.333.333,- atau 85,62\%.

Tabel 2. Pembiayaan Dalam Usaha Budidaya Ayam

\begin{tabular}{rlrrrr}
\hline \hline \multirow{2}{*}{ No } & \multicolumn{1}{c}{ Investasi } & \multicolumn{4}{c}{ Kecamatan } \\
\cline { 3 - 6 } & & Gunungpati & Persentase & \multicolumn{1}{c}{ Mijen } & Persentase \\
\hline \multirow{2}{*}{1} & Tempat pakan & 5.815 .444 & 2,56 & 6.063 .692 & $\ldots(\%) \ldots$ \\
2 & Tempat minum & 8.932 .056 & 3,93 & 7.065 .692 & 2,43 \\
3 & Baby chick & 2.925 .611 & 1,29 & 2.778 .846 & 1,12 \\
4 & Gasollec & 3.911 .111 & 1,72 & 2.600 .000 & 1,04 \\
5 & Timbangan & 1.443 .056 & 0,63 & 1.171 .154 & 0,47 \\
6 & Selang gas & 414.000 & 0,18 & 225.000 & 0,09 \\
7 & Tirai & 2.696 .944 & 1,18 & 1.646 .154 & 0,66 \\
8 & Tandon air & 1.917 .222 & 0,84 & 2.623 .077 & 1,05 \\
9 & Jenset & 3.333 .333 & 1,46 & 5.553 .846 & 2,23 \\
10 & Ember & 157.944 & 0,06 & 228.769 & 0,09 \\
11 & Kandang & 189.500 .000 & 83,55 & 213.333 .333 & 85,62 \\
12 & Sekam & 1.861 .111 & 0,82 & 1.943 .077 & 0,78 \\
13 & LPG & 165.722 & 0,07 & 178.692 & 0,07 \\
14 & Kipas & 2.844 .444 & 1,25 & 2.650 .000 & 1,06 \\
15 & Pemanas serbuk & 857.778 & 0,37 & 1.076 .923 & 0,43 \\
16 & Minyak tanah & 10.694 & 0,09 & 11.538 & 0,03 \\
\hline & Jumlah & 226.786 .470 & 100 & 249.149 .793 & 100 \\
\hline
\end{tabular}

Sumber: Analisis Data Primer, 2015.

Rata-rata modal investasi peternak ayam broiler di Kecamatan Mijen lebih besar dibandingkan Kecamatan Gunungpati, yaitu di Kecamatan Mijen sebesar Rp. 249.149.793,- dan di Kecamatan Gunungpati sebesar Rp. 226.786.470,-. Biaya investasi terbesar peternak di Kecamatan Gunungpati adalah kandang sebesar Rp. 189.500.000,- atau 83,55\% dan di Kecamatan Mijen kandang sebesar Rp. 213.333.333,- atau 85,62\%.

Rata-rata biaya total yang dikeluarkan peternak ayam broiler di Kecamatan Gunung Pati sebesar Rp. 198.003.520,04,- sedangkan di Kecamatan Mijen sebesar Rp. 183.488.974,87,-. Biaya peternak di Kecamatan Gunung Pati lebih besar dibanding di Kecamatan Mijen, hal ini karena jumlah peternak ayam broiler di Kecamatan Gunung Pati lebih besar dibanding di Kecamatan Mijen, sehingga biaya yang diperlukan juga besar. Biaya penyusutan peternak ayam broiler di 
Kecamatan Gunung Pati sebesar Rp. 757.773,32,-- atau 0,38\% sedangkan di Kecamatan Mijen sebesar 665.517,26,- atau 0,36\%. Rincian perhitungan biaya penyusutan dan rata-rata biaya total yang dikeluarkan peternak ayam broiler dapat dilihat pada Tabel 3 .

Tabel 3. Rata-Rata Biaya Total Yang Dikeluarkan Peternak Ayam Broiler

\begin{tabular}{|c|c|c|c|c|c|}
\hline \multirow[b]{2}{*}{ No. } & \multirow[b]{2}{*}{ Biaya } & \multicolumn{4}{|c|}{ Kecamatan } \\
\hline & & Gunung Pati & $\begin{array}{l}\text { Persentase } \\
\quad \ldots(\%) \ldots\end{array}$ & Mijen & $\begin{array}{c}\text { Persentase } \\
\ldots(\%) \ldots\end{array}$ \\
\hline \multirow[t]{4}{*}{1} & Biaya tetap & & & & \\
\hline & 1. Penyusutan & $757.773,32$ & 0,38 & $665.517,26$ & 0,36 \\
\hline & 2. Listrik & $911.111,11$ & 0,46 & 775.000 & 0,42 \\
\hline & Total biaya tetap & $1.668 .884,43$ & 0,84 & $1.440 .517,26$ & 0,78 \\
\hline \multirow[t]{7}{*}{2} & Biaya tidak tetap & & & & \\
\hline & $\begin{array}{l}\text { 1. Pembelian } \\
\text { DOC }\end{array}$ & $38.233 .333,33$ & 19,31 & 35.966 .615 & 19,61 \\
\hline & 2. Tenaga kerja & 2.750 .000 & 1,39 & 2.484 .615 & 1,35 \\
\hline & 3. Pakan & $150.963 .736,11$ & 76,24 & 140.357 .360 & 76,49 \\
\hline & 4. OVK & $4.387 .566,17$ & 2,22 & $3.239 . .867$ & 1,77 \\
\hline & $\begin{array}{l}\text { Total biaya tidak } \\
\text { tetap }\end{array}$ & $196.334 .635,61$ & 99,16 & 182.048 .458 & 99,22 \\
\hline & Total biaya & $198.003 .520,04$ & 100 & $183.488 .974,87$ & 100 \\
\hline
\end{tabular}

Sumber: Analisis Data Primer, 2015.

Penerimaan terbesar peternak ayam broiler di Kecamatan Gunungpati lebih besar dibandingkan di Kecamatan Mijen yaitu sebesar Rp. 212.425.615,- per Periode. Perhitungan penerimaan peternak ayam broiler, terperinci pada Tabel 4.

Tabel 4. Rata-rata Penerimaan Peternak Ayam Broiler

\begin{tabular}{|c|c|c|c|c|c|c|}
\hline \multirow[b]{2}{*}{ No. } & \multirow{2}{*}{\multicolumn{2}{|c|}{ Uraian }} & \multicolumn{4}{|c|}{ Kecamatan } \\
\hline & & & $\begin{array}{c}\text { Gunung } \\
\text { Pati }\end{array}$ & $\begin{array}{c}\text { Persentase } \\
(\%)\end{array}$ & Mijen & $\begin{array}{c}\text { Persentase } \\
(\%)\end{array}$ \\
\hline 1 & $\begin{array}{l}\text { Penjualan } \\
\text { hidup }\end{array}$ & ayam & 212.425 .615 & 100 & 200.698 .807 & 100 \\
\hline
\end{tabular}

Sumber: Analisis Data Primer, 2015.

Rata-rata biaya di Kecamatan Gunung Pati Rp. 198.003.520,04,- dan di Kecamatan Mijen Rp. 183.488.974,87,-. Rata-rata biaya di Kecamatan Gunung Pati lebih besar dibanding di Kecamatan Mijen, hal ini karena jumlah penjualan ayam hidup di Kecamatan Gunungpati lebih besar dibanding di Kecamatan Mijen. Adapun rekap rata-rata penerimaan, biaya dan pendapatan peternak ayam broiler, terperinci pada Tabel 4. 
Tabel 4. Rekap Rata-rata Penerimaan, Biaya dan Pendapatan Peternak Ayam Broiler

\begin{tabular}{|c|c|c|c|c|}
\hline No & Kecamatan & Penerimaan & Biaya & Pendapatan \\
\hline & \multicolumn{4}{|c|}{ (Rp/periode) } \\
\hline 1 & Gunung Pati & 212.425 .615 & $198.003 .520,04$ & 14.422 .095 \\
\hline 2 & Mijen & 200.698 .807 & $183.488 .974,87$ & 17.209 .832 \\
\hline
\end{tabular}

Sumber: Analisis Data Primer, 2015.

Berdasarkan uji kenormalan biaya, penerimaan dan pendapatan di Kecamatan Gunungpati dan Kecamatan Mijen menunjukkan sebaran data normal karena sign $>0,05$. Hal ini sesuai pendapat Sugiyono (2010). Bahwa daerah penolakan uji normalitas yaitu $\mathrm{H}_{0}$ diterima dan $\mathrm{H}_{1}$ ditolak bila sign $>0,05$. Sedangkan $\mathrm{H}_{0}$ ditolak dan $\mathrm{H}_{1}$ diterima bila sign $\leq 0,05$.

Rata - rata biaya peternak ayam broiler di Kecamatan Gunungpati dan Kecamatan Mijen mempunyai signifikansi $=0,627>(0,05), \mathrm{H}_{0}$ diterima $\mathrm{H}_{1}$ ditolak (non signifikan), berarti tidak ada perbedaan biaya antara peternak ayam broiler di Kecamatan Gunungpati dengan Kecamatan Mijen. Biaya di Kecamatan Gunungpati Rp 198.003.520,04 dan di Kecamatan Mijen Rp 183.488.974,87. Tidak ada nya perbedaan biaya disebabkan adanaya beberapa peternak yang tidak sebanding antara jumlah tenaga kerja dengan populasi ayam yang dipelihara.

Rata-rata penerimaan peternak ayam broiler di Kecamatan Gunungpati dan Kecamatan Mijen mempunyai signifikansi $=0,717>(0,05), \mathrm{H}_{0}$ diterima $\mathrm{H}_{1}$ ditolak (non signifikan), berarti tidak ada perbedaan penerimaan antara Kecamatan Gunungpati dan Kecamatan Mijen. Rata-rata penerimaan di Kecamatan Gunungpati Rp 212.425.615 dan di Kecamatan Mijen Rp 200.698.807 hal ini disebabkan karena jumlah penjualan yang hampir sama antara peternak ayam broiler di Kecamatan Gunungpati dan Kecamatan Mijen.

Rata-rata pendapatan peternak ayam broiler di Kecamatan Gunungpati dan Kecamatan Mijen mempunyai signifikansi 0,653 > $(0,05), \mathrm{H}_{0}$ diterima $\mathrm{H}_{1}$ ditolak (non signifikan), berarti tidak ada perbadaan pendapatan antara Kecamatan Gunungpati dan Kecamatan Mijen. Rata-rata pendapatan di Kecamatan Gunungpati Rp 14.422.095 dan di Kecamatan Mijen Rp 17.209.832, hal ini karena terjadi keseimbangan antara biaya dan pnerimaan antara Kecamatan Gunungpati dan Kecamatan Mijen.

\section{KESIMPULAN DAN SARAN}

Berdasarkan hasil dan pembahasan, dapat diambil suatu kesimpulan sebagai berikut: 1) Rata-rata biaya peternak ayam broiler di Kecamatan Gunungpati Rp 198.003.520,04 dan di Kecamatan Mijen Rp 183.488.974,87. 2) Rata-rata penerimaan peternak ayam broiler di Kecamatan Gunungpati Rp 212. 425.615 dan di Kecamatan Mijen Rp 200.698.807. 3) Rata-rata pendapatan peternak ayam broiler di Kecamatan Gunungpati Rp 14.422 .095 dan di Kecamatan Mijen Rp 17.209.832.

Berdasarkan hasil penelitian yang dilakukan di Kecamatan Gunungpati dan Kecamatan Mijen disarankan peternak ayam broiler lebih mengefisienkan biaya terutama dalam penyesuaian antara tenaga kerja dan jumlah populasi ternak. 


\section{DAFTAR PUSTAKA}

AAK. 1986. Beternak Ayam Pedaging. Penerbit Kanisius, Yogyakarta.

Badan Pusat Statistik Kecamatan Gunungpati dan Mijen Tahun 2014.

Badan Pusat Statistik Kota Semarang Tahun 2014.

Direktorat Jendral Peternakan Kementrian Pertanian. Statistik Tingkat Konsumsi Daging Ayam Broiler di Indonesia Tahun 2013.

Fadilah, R. 2013. Beternak Ayam Broiler. PT. Agro Media Pustaka, Jakarta.

Hernanto, R. M. 1993. Ilmu Usaha Tani. Edisi Ke II. Penebar Swadaya, Jakarta.

Prawirokusumo, S. 1991. Ilmu Usaha Tani. BPFE, Yogyakarta.

Rasyaf, M. 2000. Manajemen Peternakan Ayam Broiler. Penebar Swadaya, Jakarta.

Rasyaf, M. 2002. Memasarkan Hasil Peternakan Cetakan Kedua. Penerbit Penebar Swadaya, Jakarta.

Sugiyono. 2010. Statistika Untuk Penelitian. Penerbit Alfabeta, Bandung. 